\title{
MEMBERDAYAKAN MASYARAKAT PEDULI,CERDAS DAN BERSOSIAL SEHINGGA MAMPU BERSAING DI ERA GLOBALISASI DI DESA LEUWIMEKAR SUKAMULYA
}

\author{
Rulhendri $^{1}$, Martin Jafar Nugraha, Anggi Nurohman ${ }^{2}$ \\ rulhendri@gmail.com \\ Dosen Fakultas Teknik ${ }^{1}$, Mahasiswa KKN Kelompok 58 Tahun $2018^{2}$
}

\begin{abstract}
ABSTRAK
Pendidikan adalah upaya mengembangkan potensi-potensi keilmuan peserta didik baik potensi fisik potensi cipta, rasa maupun karsanya, agar potensi itu mejada nyata dan dapat berfungsi dalam perjalanan hidupnya sebagai individu dan masyarakat. Dasar pendidikan adalah cita-cita kemanusiaan universal. Pendidikan bertujuan menyiapkan pribadi dalam keseimbangan, kesatuan, organis, harmonis, dinamis. Guna mencapai tujuan hidup kemanusian. Oleh sebab itu, perguruan tinggi berupaya mewujudkan bibit-bibit penerus bangsa berkualitas secara nyata dengan melaksanakan berbagai upaya strategis bagi mahasisanya. Seluruh upaya yang digariskan oleh sebuah perguruan tinggi seyoginya tidak terlepas dari visi dan misi perguruan tinggi sebagaimana yang lebih dikenal dengan Tri Dharma Perguruan Tinggi. Tri Dharma Perguruan Tinggi merupakan jargon yang semetinya didengungkan dengan tiga aspek sebagai acuannya, yakni Pendidikan dan Pengajaran, Penelitian dan Pengembangan, dan Pengabdian Kepada Masyarakat.
\end{abstract}

\section{Kata Kunci : Pendidikan, Pengabdian dan Potensi}

\section{PENDAHULUAN}

Desa Leuwimekar adalah salah satu Desa yang terdekat kepada kantor Kecamatan Leuwiliang dimana Kecamatan itu memiliki 14 Desa, desa leuwimekar khusunya kampung Sukamulya berada pada letak geografis yang tinggi atau berbukit sehingga sangat jarang ditemukannya air bersih dan memiliki luas 1.026 Ha. Dan memiliki batas desa sebagai berikut :

\begin{tabular}{|c|l|c|}
\hline No & Keterangan & Berbatasan \\
\hline 1 & Utara & Desa Leuwiliang \\
\hline 2 & Selatan & Desa Barengkok \\
\hline 3 & Barat & Desa Cibebeur \\
\hline 4 & Timur & Desa Sadeng \\
\hline
\end{tabular}

Desa Leuwimekar dikelilingi oleh gunung salak Bogor dan bias dikatan desa ini adalah kaki gunung salak, memiliki lahan perswahan pekebunan manggis dan durian yang luas, banyak bangunan villa dan beberapa bangunan sekolah Tk,SD,SMP,dan SMK, namun terhadap faham akan pentingnya ilmu pendidikan dan kesadaran membangun dalam memanfaatkan letak geografis membuat masyarakat sekitar desa sedikit tertinggal dari segi sudut pandang dan paradigma masyakat, kultur dan adat yang masih kental juga menjadi salah satu factornya, desa Leuwimekar dekat dengan lokasi wisata alam, Rumah Pohon Pabangbon dan Bukit Bintang serta Wisata Curug Koneng. 


\section{METODE PELAKSANAAN}

\section{Tahap Pelaksanaan}

Pelaksanaan KKN kelompok 3 Desa Situ Daun ini terhitutng dari tanggal 7 Agustus 2018 sampai dengan tanggal 5 September 2018 dengan tahapan pelaksanaan permingu, berjumlah 4 tahapan. Adapun tahap pelaksanaan sebagai berikut :

\begin{tabular}{|c|c|c|}
\hline Tahap pelaksanaan & Metode & Hasil yang diharapkan \\
\hline $\begin{array}{l}\text { Bimbingan Belajar } \\
\text { Hari Sore } \\
\text { Agama Islam dan } \\
\text { Matematika) }\end{array}$ & $\begin{array}{l}\text { 1. Teori } \\
\text { 2. Tanya Jawab } \\
\text { 3. Sharing } \\
\text { 4. Peraktik } \\
\text { Percakapan }\end{array}$ & $\begin{array}{l}\text { 1. Pemahaman mata pelajaran } \\
\text { sekolah } \\
\text { 2. Menigkatkan kualitas Anak } \\
\text { didik } \\
\text { 3. Mampu menghitung dengan } \\
\text { cepat } \\
\text { 4. Fasih berbahasa Ingris } \\
\text { 5. Akhlak Terpuji }\end{array}$ \\
\hline Pelatiahn Komputer Dasar & $\begin{array}{l}\text { 1. Teori } \\
\text { 2. Peraktik (Jika } \\
\text { Ketersedian alat } \\
\text { ada) }\end{array}$ & $\begin{array}{l}\text { 1. Mengenal Teknologi Ms.Ofice } \\
\text { 2. Mampu Membuat Laporan } \\
\text { Administrasi } \\
\text { 3. Mengetik Cepat }\end{array}$ \\
\hline $\begin{array}{l}\text { Kreasi makanan untuk } \\
\text { produk ekonomis }\end{array}$ & $\begin{array}{l}\text { 1. Ceramah } \\
\text { 2. Peraktik }\end{array}$ & $\begin{array}{l}\text { 1. Memahami produk local } \\
\text { 2. Mampu berjualan dengan } \\
\text { sehat } \\
\text { 3. Kreatif dalam mengemas } \\
\text { produk makanan ringan }\end{array}$ \\
\hline Penyuluhan PHBS & $\begin{array}{l}\text { 1. Ceramah } \\
\text { 2. Tanya Jawab } \\
\text { 3. Praktik }\end{array}$ & $\begin{array}{l}\text { Terbiasanya Hidup Bersih dan } \\
\text { cinta akan kesehatan }\end{array}$ \\
\hline
\end{tabular}




\begin{tabular}{|c|c|c|}
\hline Perpustakaan Alam & $\begin{array}{ll}\text { Pengadaan } & \text { Buku } \\
\text { Layak baca } & \end{array}$ & $\begin{array}{l}\text { 1. Menghilangkan Buta Aksara } \\
\text { 2. Menambah Pengetahuan } \\
\text { 3. Memanfaatkan Lahan kebun } \\
\text { yang rindang }\end{array}$ \\
\hline $\begin{array}{l}\text { Penuluhan } \quad \text { Menabung } \\
\text { Sejak dini }\end{array}$ & $\begin{array}{l}\text { 1. Ceramah } \\
\text { 2. Praktik }\end{array}$ & $\begin{array}{llr}\text { Anak-anak } & \text { faham } & \text { akan } \\
\text { pentingnya } & \text { menabung untuk } \\
\text { mandiri } & & \end{array}$ \\
\hline Ekonomi Kreatif & $\begin{array}{l}\text { 1. Ceramah } \\
\text { 2. Peraktik }\end{array}$ & $\begin{array}{l}\text { 1. Masyarakat mampu } \\
\text { memanfaatkan barang barang } \\
\text { bekas } \\
\text { 2. Masyarakat lebih kreatif dan } \\
\text { inovatif }\end{array}$ \\
\hline
\end{tabular}

\section{Metode Pendekatan}

Dalam melaksanakan penelitian ini kami menggunakan jenis penelitian yang bersifat field research atau penelitian lapangan yaitu penelitian yang dilakukan langsung kelapangan atau terjun langsung kemasyarakat Sukamulya untuk meperoleh data-data yang dibutuhkan. Kamipun melakukan penelitian berdasarkan analisis data yang didapatkan dari lapangan/aparatur kampung dan desa dan juga para tokoh agama. Dalam metode pendekatan ini kami menggunakan beberapa pendekatan antara lain :

Pendekatan Sosialogis : Pendekatan ini bertujuan untuk mengetahui kondisi kehidupan masyarakat sehari-hari.

Pendekatan Psikologis : Pendekatan ini bertujuan untuk melihat kondisi yang menjadi objek penelitian. Adapun metode yang digunakan dalam pengumpulan data yang kami gunakan yaitu dengan observasi langsung kondisi kampung dan kegiatan masyarakat di kampung Sukamulya Desa Leuwimekar, kemudian kami juga menggunakan metode wawancara dengan para sepuh dan tokoh agama setempat, dan dalam pengumpulan data ini ada beberapa sumber data yang penulis kumpulkan yaitu:

Data yang bersifat primer yaitu suatu data yang kami dapatkan dari sumbersumber yang terpercaya seperti aparatur kampung dan desa serta tokoh masyarakat kampung Sukamulya. Adapun sampel yang dijadikan lokasi penelitian adalah Desa Leuwimekar Kampung Sukamulya Rw 01 Rt 01.

Analisa data yang digunakan adalah data kualitatif yang dilakukan semenjak sebelum memasuki lapangan, selama dilapangan dan selesai dilapangan, namun dalam menganalisa data lebih difokuskan selama proses dilapangan bersma dengan pengumpulan data.

\section{Partisipasi Masyarakat dalam Program}

1. Partisipasi masyarakat yang dapat dilakukan dalam kegiatan ini adalah sebagai berikut :

2. Kepala Desa dan Staff membantu mencari lokasi titik focus lokasi KKN 
3. Staff Desa, Ketua RT dan Ketua Pemuda membantu mencari tempat hunian selama KKN

4. Bersama ibu RT mencari peserta keaksaraan fungsional

5. Mengizinkan dan mendukung anakanak untuk mengikuti Les Bimbingan Belajar

6. Mempersiapkan tempat untuk penyuluhan

7. Mempersiapkan tempat untuk Senam Pagi

8. Bersama dengan pemuda dan Ketua RT menyusun perlombaan dalam rangka memperingati hari kemerdekaan RI

9. Mengizinkan dan mendukung pemasangan Spanduk dan Plang Majelis

10. Mempersiapkan alat kebersihan dan kerjabakti Bersama Menurut Eska dalam Jurnal Abdi Dosen Pemberdayaan kesehatan merupakan kegiatan penambahan pengetahuan yang diperuntukan bagi masyarakat melalui penyebaran pesan.

11. Mempersiapkan Aula untuk pengajaran Ngaji kepada anak-anak

\section{Langkah Evaluasi}

Evaluasi yang akan dilakukan terdiri dari :

1. Evaluasi proses, yang terkait dengan perencanaan, pelaksanaan dan monitoring kegiatan. Evaluasi proses akan dilakukan setiap pekan Bersama dengan Kelompok

2. Evaluasi hasil, yang akan dilaksanakan setelah kegiatan dilaksanakan. Eavaluasi hasil bertujuan untuk mempertimbangkan agenda-agenda yang akan dilaksanakan selama KKN berlangsung.

\section{HASIL DAN PEMBAHASAN}

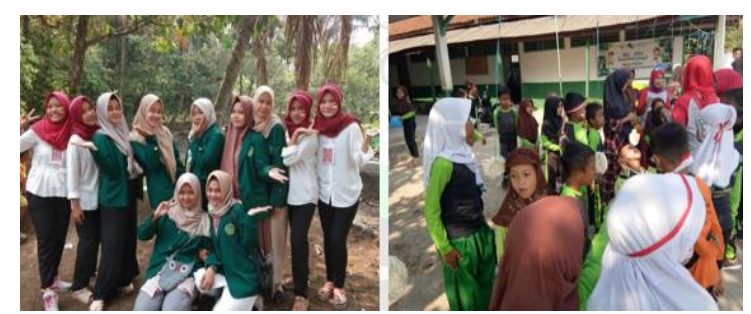

Kegiatan Lomba di MI PUI KandangSapi

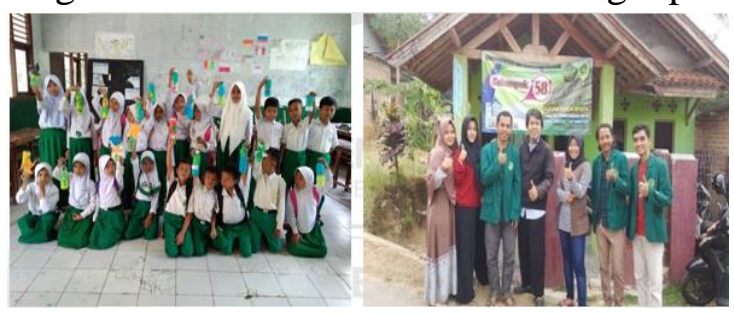

Pembuatan Celengan dari botol bekas

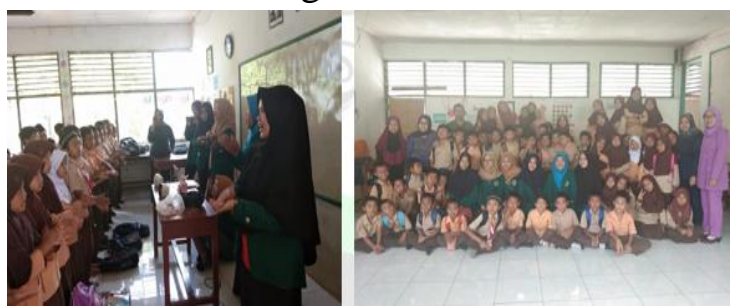

Kegiatan Penyuluhan Cuci Tangan

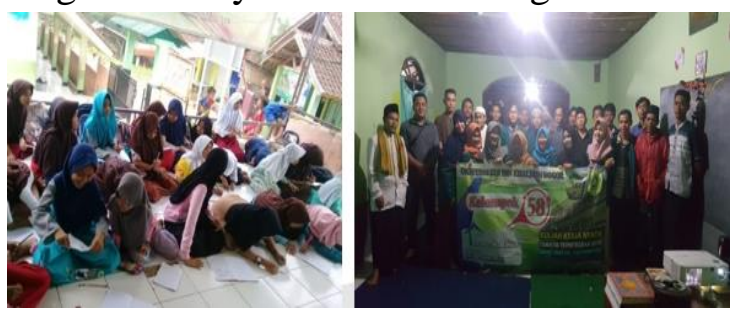

Pada saat Les Bahasa Inggris

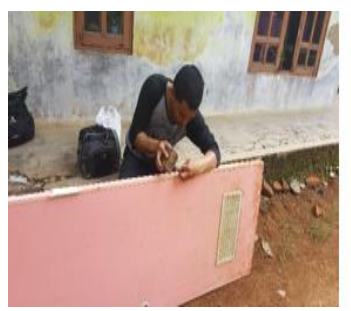

Perbaikan MCK

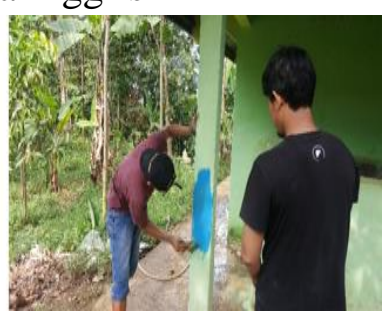




\section{KESIMPULAN}

Secara umum dengan melihat kinerja rekan-rekan semuanya dalam upaya mensukseskan kegiatan KULIAH KERJA NYATA TEMATIK TAHUN 2018 sangat kami apresiasi dan memberikan penghargaan yang sebesar-besarnya kepada seluruh anggota KKN 58 DESA LEUWIMEKAR Bogor dengan penuh keikhlasan, tanggung jawab dan komitmennya secara sungguh-sungguh. Kami sadar bahwa segala bentuk kekurangan kami itu tidak terlepas dari kebodahan kami juga selaku Mahasiswa yang masih dalam berproses mencari nilainilai kebenaran, kami juga sadar bahwa segala bentuk kelebihan yang kami berikan itu tidak terlepas dari kehendak yang maha kuasa yang senantiasa memberikan kemudahan kepada umatnya.

\section{REFEREENSI}

Administrasi Profil Desa Leuwimekar

Eska Perdana Prasetya (2017), Pemberdayaan Masyarakat Tentang Kesehatan, Pendidikan Dan Kreatifitas, Jurnal Abdi Dosen

LPPM : Universitas Ibn Khaldun Bogor (2018), Petunjuk Pelaksanaan Terintegrasi 2018 